\title{
NEOPUNITIVISMO Y CONTROL SOCIAL. REFLEXIONES SOBRE LA REPRESIÓN SELECTIVA DE LA POLÍTICA POPULISTA
}

\section{Neo-punitivism and Social Control. Reflection of the Selective Repression of Populist Politics}

Neopunitivismo e controle social. Reflexões sobre a repressão seletiva da política populista

\section{RECIBIDO: 17 DE NOVIEMBRE DE 2014}

es

\section{RESUMEN}

Análisis crítico de las reformas penales inflacionarias planteadas por el discurso neopunitivista de la política con fines electoralistas, masificado irresponsablemente por los medios de comunicación y que pretende utilizar al derecho penal como un arma política de control social en todas las relaciones y conflictos humanos, flexibilizando los principios fundamentales de fragmentariedad, subsidiariedad y ultima ratio. Además, en una interesante contraposición con la realidad represiva descrita, se plantean dos novedosas excepciones: medidas alternativas a la pena de prisión del anteproyecto del nuevo Código Penal argentino, y una decisión judicial de declarar inconstitucional el mínimo legal previsto para un delito por la insignificancia en la afectación al bien jurídico tutelado.
EVALUADO:19DE DICIEMBRE DE 2014

Ramiro Traverssa (Argentina) Abogado, especialista en Derechos Fundamentales y Garantías Constitucionales en la Justicia Penal

Universidad Nacional de Córdoba

ramirotraverssa@hotmail.com

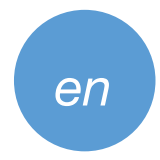

\section{ABSTRACT}

This article is a critical analysis of inflationary criminal reforms set out by the neo-punitivism theory of politics for electioneering purposes. This theory has been irresponsibly disseminated by the media and tries to use criminal law as a political weapon of social control in every human relation and concept by increasing flexibility on the fundamental principles of fragmentary and subsidiary nature and ultima ratio. Additionally, as an interesting contraposition with the repressive reality described, we propose two new exceptions: alternative measures to imprisonment (new Argentinian Penal Code draft bill) and a court decision to declare unconstitutional the minimum legal time stated by the law for a crime due to the triviality in the encumbrance of the legally protected right.
PALABRAS CLAVE: neopunitivismo, control social, medidas alternativas a la prisión.
KEYWORDS: neo-punitivism, social control, alternative measures to imprisonment.
ACEPTADO:26 DE DICIEMBRE DE 2014 
Allí donde llueven leyes penales continuamente, donde entre el público a la menor ocasión se eleva un clamor general de que las cosas se remedien con nuevas leyes penales o agravando las existentes, ahí no se viven los mejores tiempos para la libertad - pues toda ley penal es una sensible intromisión en la libertad, cuyas consecuencias serán perceptibles también para los que la han exigido de modo más ruidoso-, allí pude pensarse en la frase de Tácito: Pessima respublica, plurimae leges.

Von Bar (1882, p. 334)

\section{INTRODUCCIÓN}

Resulta casi inevitable que el canal institucional por el que se instrumentan las pretensiones punitivas de una sociedad se encuentre en una constante inestabilidad, con signos de permanente provisionalidad. Esta cuestión se ve reflejada como una crisis del derecho penal contemporáneo, que parece no cuestionar la idea rectora sobre los límites del ius puniendi, sino que se deriva de la tensión expansiva a que se está sometiendo el derecho penal para afrontar exitosamente la lucha contra una criminalidad que se afirma en franca expansión. Este discurso neopunitivista - entendido ello como la corriente político-criminal que se caracteriza por la renovada creencia mesiánica de que el poder punitivo puede y debe llegar a todos los rincones de la vida social- enarbolado por sectores de pensamiento autoritario, y direccionado hacia determinados grupos sociales etiquetados de peligrosos, intenta justificarse en tales afirmaciones y pone en jaque a la ciencia jurídica que debe dar respuestas concretas a estos requerimientos de reformas legislativas expansivas e interpretaciones jurisdiccionales amplias de la normativa penal. Así lo sostiene Maier cuando afirma:

\section{la expansión del Derecho penal es el fenómeno más visible y tangible: el Derecho penal logra, cotidianamente, nuevos ámbitos de relaciones para su regulación, que ya casi interesa a todas las relaciones sociales entre los seres humanos o entre ellos y el Estado (Maier, 2006, p. 295).}

Asimismo, algunos creen que el derecho penal se encuentra en una metamorfosis para consolidarse, de una vez y para siempre, como una efectiva herramienta de control social, por lo que su "insostenible situación
[...] constituiría precisamente la consecuencia esencial del proceso de modernización fragmentaria y contradictoria que experimenta el sistema punitivo en esa 'maduración' supuestamente necesaria para su adaptación a las exigencias de las sociedades modernas" (Silva, 2003, p. XII). En efecto, somos espectadores de una variada oferta de conceptos populistas para la represión de la "criminalidad organizada", de los delitos violentos y del extremismo político, de programas de "modernización" del derecho penal. La ampliación de las facultades de investigación de la policía, la aceleración de los procesos penales, la anticipación de la punibilidad o la agravación de las penas aparecen como líneas rectoras de la discusión.

Quien se detenga a estudiar la situación actual del ius punidendi estatal como práctica que pretende solucionar los más variados conflictos en la vida social, tocándole intervenir de la forma más enérgica frente a los casos que se suponen más graves, "comprobará inmediatamente que vivimos un tiempo en el cual el derecho punitivo ha sido elevado a la categoría de octava maravilla del mundo" (Pastor, 2005, p. 5). Se habría pasado así de un "derecho penal liberal", interpretado desde una política criminal orientada al aseguramiento de los derechos individuales del acusado, a un "derecho penal liberado" de tales límites y controles que se orienta al combate de la criminalidad como cruzada contra el mal (Sánchez, 2003).

En efecto, de la irresponsable fantasía abolicionista que surgió hace algunas décadas hemos pasado, sin prestar atención al sensato llamado del derecho penal mínimo, como si este hubiera sido en verdad el canto de sirena, a una desbordante explosión de nuevas figuras penales y a una lluvia de interpretaciones judiciales que extienden el ámbito de la responsabilidad penal más allá de lo razonable en el caso de tipos abiertos (característico: el delito imprudente, pero también los delitos dolosos de funcionarios). Hemos alcanzado el relajamiento de todos los límites y de todos los controles jurídicos a favor de la persecución y el castigo de los crímenes considerados más graves (derechos humanos, corrupción, terrorismo, drogas) y a una euforia de "lo penal" como "sanalotodo" social que no tiene precedentes (Maier, 2006).

Las marcadas diferencias sociales, con notables desigualdades en el acceso a los más elementales derechos, como 
la vivienda digna, el alimento, la educación, la salud pública y el trabajo, dificultan proveer la prevención primaria (promoción de la movilidad vertical mediante el aumento y la redistribución de la renta), y el deterioro de la prevención secundaria (la gran corrupción en los servicios de seguridad) suele tener como única respuesta la "clientelista" reforma de las leyes penales, en abierto fraude a la opinión pública, lo que no hace más que crear confusión política, abrir nuevos espacios de deterioro de la prevención secundaria y degradar la seguridad jurídica con lesión gravísima a la legalidad y certeza de la ley penal, agravada por la selectividad punitiva como correlato inevitable de la estratificación y de la reducida movilidad vertical. La res publica, o la cosa pública, entendida como ese elemento que nos pertenece a todos y a cada uno de nosotros como miembros de una sociedad civil con democracias consolidadas, parece orientar su línea de discusión de las problemáticas sociales actuales hacia el inmediato y permanente requerimiento del derecho penal como única respuesta y herramienta de transformación social. Las actuales demandas de criminalización parecen canalizarse a través de todos los partidos políticos y ser exaltadas por los monopolios de comunicación masiva, frente a una sociedad cada vez más estratificada, cuyos sectores más liberales reclaman por mayores penas y nuevas cárceles; y han sido formuladas en relación con el debate sobre la persecución punitiva a los consumidores de estupefacientes, la proliferación de inmigrantes ilegales, la prostitución callejera, las protestas sociales, el aborto clandestino, la homosexualidad, etc. Sin embargo, aunque "es más que cuestionable que el Derecho penal pueda solucionar éstos y otros problemas sociales tan complejos, sí puede constatarse que sin lugar a dudas el Derecho penal posee actualmente el carácter de arma política” (Albrecht, 2000, p. 472).

En este orden de ideas, en casi todo el mundo, las llamadas campañas de ley y orden (law and order; Gesetz und Ordnung) del siglo pasado han sido reemplazadas por un juego político permanente, en el cual se observa una clara tendencia a fomentar la represión selectiva por parte de los sectores conservadores de la política y, a decir verdad, también por los sectores progresistas ante la amenaza de perder votos. Ejemplos de esta naturaleza lo han dado el laborismo inglés, el socialismo italiano, la socialdemocracia alemana y el propio partido demócrata estadounidense. Esta drástica situación ha hecho que hoy, en la mayoría de las sociedades, las apuestas a mayor represión y las respectivas respuestas en el mismo sentido, todas con fines electoralistas y clientelistas coyunturales - aunque algunas con ultraintenciones muy peligrosas-, abran un panorama en que la dignidad de la persona y los límites al poder punitivo del Estado de derecho se hallan en constante riesgo, cuando no abiertamente lesionados, con bastante indiferencia de los organismos internacionales, en manos de los representantes de esos mismos Estados y que, permanentemente, se ocupan de proponer o imponer tratados que obligan a la tipificación, muchas veces de conductas que están ya conminadas, con lo cual introducen más confusión en las legislaciones nacionales (Zaffaroni, 2013). Ese derecho penal, cuya partida de nacimiento todos conocemos, así como conocemos su razón de ser (domesticar el poder soberano, expresado por su forma más violenta, mediante reglas jurídicas que lo limitan en su ejercicio, pero, al mismo tiempo, lo reconocen $y$ legitiman), que por y para ello transfiere el uso de la fuerza - salvo un caso genérico específico fundado en la necesidad - al poder político centralizado, con la finalidad de evitar la reacción directa del ofendido, cuyos principios y características todos hemos debido declamar como una oración en una ceremonia religiosa, está siendo hoy en día, aun sin nombrarlo, objeto de enormes cambios que, si bien no pretendo agotar, sí quiero destacar como características salientes.

\section{DERECHO PENAL, POLITICA Y SOCIEDAD}

Nuestras sociedad puede definirse todavía mejor como la sociedad de la "inseguridad sentida" (o como la sociedad del miedo). En efecto, uno de los rasgos más significativos de las sociedades de la era posindustrial es la sensación general de inseguridad o, esto es, la aparición de una forma especialmente aguda de vivir el riesgo. Son ciertos, desde luego, los "nuevos riesgos". Pero asimismo lo es que la propia diversidad y complejidad social, con su enorme pluralidad de opciones, con la existencia de una sobreinformación a la que se suma la falta de criterios para la decisión sobre lo que es bueno o malo, sobre en qué se puede confiar y en qué no, constituye un germen de dudas, incertidumbres, ansiedad e inseguridad. La expansión del sistema del derecho penal, asentada en los aspectos ya comentados, responde, asimismo, a un fenómeno general de identificación social con la víctima (sujeto pasivo) del delito antes que con el autor (sujeto activo) (Silva, 2003).

Así, entonces, los mecanismos formales y materiales del derecho penal están orientados, cada vez más, a la
Neopunitivismo y control social. Reflexiones sobre la represión selectiva de la política populista 
víctima, de acuerdo con el pensamiento de la eficiencia preventiva (Albrecht, 2000). Así, advertimos cómo el discurso político represivo cuestiona los sistemas penales garantistas argumentando que son diseñados pensando en el delincuente, y no en el ciudadano honesto y trabajador — posible víctima-, y pone su mira en ciertos grupos sociales con perfiles peligrosistas.

Entonces, la finalidad de la limitación preventiva de riesgo justifica todas las más variadas formas de intervención estatal, desde los medios de investigación encubiertos hasta las escuchas en las viviendas, con lo cual se deforma el derecho penal material y formal. Resulta que no es un autor individual, sino determinados grupos sociales o las condiciones de vida lo que está bajo sospecha. Parece, entonces, que pertenecer a determinadas minorías implica reunir las condiciones necesarias para convertirse en una amenaza social y necesitar de inmediato la reacción del derecho penal. En consecuencia, el fundamento de la pena en esta tesis es la estabilidad social: "el Derecho tiene la función de garantizar la orientación de acciones y la estabilidad de expectativas" (Jakobs, 1997, p. 6). Tiene asignada la función de evitar las consecuencias negativas de la violación de la ley para la estabilidad del sistema y para la confianza en la vigencia del derecho. Con ello, se abandonan los dos baluartes construidos por el pensamiento penal liberal para limitar la actividad punitiva del Estado frente al individuo: el principio del delito como lesión de bienes jurídicos y el concepto del culpabilidad como límite de la responsabilidad y de la pena (Albrecht, 2000, p.473).

En efecto, se observa un abandono del bien jurídico individual para girar hacia una clara concepción de protección del sistema.

Se ha logrado pasar de un derecho penal que se refería básicamente al pasado, al hecho histórico sucedido, sin ignorar que alguien era su autor, a un derecho penal que se refiere al futuro, insondable para los seres humanos, que no pueden predecirlo y, por ello, referido, en definitiva, más a la persona que se considera "peligrosa" por síntomas de riesgo que anuncian un resultado futuro meramente eventual, cuyo acaecimiento, en realidad, se ignora y hasta carece de interés analítico (Maier, 2006, p. 300).

La intervención política en el derecho penal tras136 | lada constantemente los problemas estructurales a la aplicación individual del derecho penal. Además, la actividad legislativa conduce rápidamente a resultados concretos y a producir efectos políticos inmediatos que pueden parecer intervenciones innecesarias. Tales intervenciones se elevan por encima del horizonte de la relevancia política cuando el triunfo electoral está en duda. Parece ser que el derecho penal sirve de plataforma política a través de propuestas populistas de reforma legislativa que garanticen la seguridad común, sin importar la congruencia del sistema o los límites constitucionales y supranacionales al ius puniendi estatal. En consecuencia, la normativa penal no sirve únicamente como una herramienta de la persecución penal, sino que aparece como un elemento aglutinante de los valores y normas sociales; y casi toda discusión política encuentra en el ámbito legislativo su principal contención. Así, las propuestas y discusiones sobre nuevos tipos penales y criminalizaciones parecen indicarnos cuáles son las valoraciones sociales especialmente significativas y susceptibles de protección. En este sentido, y a modo ilustrativo, se observa con preocupación el abandono por parte del máximo Tribunal constitucional alemán ${ }^{1}$ de la tesis clásica de la lesión o puesta en peligro del "bien jurídico protegido" - que sirve de límite concreto en la expansión represiva de la ley penal-, para tildarla de inconstitucional y antidemocrática, al no ser formulada por el legislador electo popularmente y, por consiguiente, plantear una nueva posición de "proporcionalidad con el sistema" de las prohibiciones penales que prima facie abriría la puerta a nuevas y numerosas reformas legislativas - aunque no protejan un bien jurídico concreto y determinado-, siempre y cuando tengan su génesis en el Parlamento y sean proporcionales (cf. Burchard, 2012).

El uso político del derecho penal, que satisfacen las supuestas demandas sociales de endurecimiento efectivo de la ley para una mayor seguridad, se presenta como un peligroso instrumento de comunicación que permite trasladar los problemas y conflictos sociales a un tipo de análisis específico. Además, la criminalidad tiene valor comercial para los medios de comunicación que lo utilizan como una mercancía de la industria cultural. Asistimos entonces a una lamentable teatralización de la persecución penal, aprovechada por los partidos políticos — con fines electoralistas - y masificada

1 Resolución de Tribunal Constitucional Alemán (Bundesverfassungsgericht), Sala Segunda de fecha 26/2/2008 en causa 2 BvR 392/07. Recuperdo de http://www.bundesverfassungsgericht.de/en/decisions/rs20080226_2bvr039207.htm 
por la prensa para vender más periódicos, con un único resultado: la relativización de los derechos fundamentales y las garantías constitucionales de los individuos, y una sociedad cada vez más reprimida y adicta al sistema penal.

\section{LA FLEXIBILIZACIÓN DE LOS LÍMITES Y LAS GARANTÍAS DEL DERECHO PENAL}

Una concepción de la ley penal como Magna Charta no solo del delincuente — según la caracterización de Von Liszt (1999)—, sino también —e incluso sobre todode la víctima, de entrada no puede dejar de tener consecuencias en el modo de concebir el principio de legalidad. En efecto, partiendo del concepto clásico, se ha señalado que los tipos penales son susceptibles de una interpretación restrictiva (normalmente, de base teleológica) e incluso de una propia "reducción teleológica" (Hillenkamp, 1981). Del mismo modo, se ha admitido por muchos - como correlato natural de lo anteriorel recurso a la analogía en el ámbito de las eximentes y atenuantes (en particular, en las causas de justificación). Pues bien, desde una perspectiva que entienda que la ley penal es también la Magna Charta de la víctima, algo que parece estar en clara consonancia con la autocomprensión de la sociedad de la inseguridad, resulta claro que ni la reducción teleológica de los tipos ni la aplicación analógica de las eximentes, en particular de las causas de justificación, se manifestarían como procedimientos incontestados. En cambio, se plantearía como cuestión por considerar la relativa a la interpretación restrictiva de las eximentes (o de ciertas eximentes) e incluso la modificación de las fronteras entre la interpretación extensiva de los tipos y la prohibida analogía in malam partem (Silva, 2003).

El derecho penal en un Estado de derecho liberal debe tener un carácter fragmentario y, por consiguiente, regir el principio de subsidiariedad, interpretada en el sentido de que este únicamente tiene lugar donde otros medios han fracasado. Además, constituye la ultima ratio en el instrumentario de que dispone el legislador, quien, según Karl Binding, deja "que las olas de la vida diaria [...] traigan a sus pies las conductas que luego él recoge para convertirlas en supuestos de hecho de delitos porque resultan insoportables" (1902, p.27). Pero solo como último recurso en las infracciones más graves y utilizado restrictivamente. En efecto, los principios programáticos de subsidiariedad y ultima ratio se dirigen clarísimamente al legislador penal. Deben, por ello, servirle como medida con la que medir eficazmente, proporcionándole así criterios con los que decidir qué modalidades de conducta son hechos penales, y que por eso debe y puede prohibir (Prittwitz, 2000, p. 434).

Ahora bien, el problema comienza a tener entidad cuando la sociedad cree que esos postulados, en vez de protegerla, resultan una debilidad del sistema, que la pone en franco peligro frente a los potenciales delincuentes. Así, parece justificarse muchos estados de excepción a los límites del derecho penal: un discurso represivo que se masifica y demanda inexorablemente a los miembros del Parlamento flexibilizar dichas limitaciones empíricas y normativas en pos de reprimir en forma inflacionaria nuevas y diversas conductas, y a los miembros del poder judicial aplicar la norma con absoluta determinación y "mano dura" aleccionando al resto de la sociedad.

La pérdida del principio de subsidiariedad y, con él, el de la concepción del derecho penal como ultima ratio de la política social, y, unido a ello, el extravío del carácter fraccionario que tradicionalmente se le atribuyó a partir del principio nullum crimen, conduce, como muchas veces sucede, a la "bastardización" del instrumento como mecanismo útil para la política social y para quienes la soportan. De ahí la afirmación de la transformación del derecho penal en una regulación jurídica simbólica, que sirve a intereses particulares, como la "demagogia política y el espectáculo mediático", con el agravante de que, a través de la Administración de Justicia, no solo confirma, sino que reafirma y agrava su carácter selectivo.

La preocupación por elaborar nuevas figuras penales que satisfagan los reclamos de los sectores represivos ha cambiado su objeto de estudio: la principal preocupación actual se enfoca en la parte especial o en el catálogo de delitos y penas, y deja en un segundo plano la parte general o de los fundamentos y límites de la imputación personal. Así se observa, desde el punto de vista procesal, que han perdido importancia el juicio y sus garantías para el imputado y, en cambio, resultan hoy trascendentes los modos alternativos de obtener una condena o una solución del conflicto y la ampliación de los métodos probatorios. En verdad, ha perdido interés, desde el punto de vista político, el desarrollo de un sistema de límites y garantías, el desarrollo de ciertos valores básicos atribuidos al ser humano, que conducían el
Neopunitivismo y control social. Reflexiones sobre la represión selectiva de la política populista 
sistema, para ocupar ese lugar la importancia de un criterio meramente práctico y "eficientista" de impulsar al derecho penal y procesal penal. Aquí se produce, como consecuencia del fenómeno disfuncional del neopunitivismo, una afectación de los fundamentos axiológicos de la jurisdicción penal, en general justificada únicamente en simples criterios de eficiencia y lucha contra el crimen (Ferrajoli, 2001). Así pues, bajo la invocación de lograr eficacia en la persecución y el castigo de los delitos y ante la enorme cantidad de procesos que inevitablemente genera el neopunitivismo con su política criminal inflacionaria, se ha recurrido a instrumentos inconstitucionales que derogan los valores que insoslayablemente deben ser respetados por el sistema penal de un Estado constitucional de derecho. Un claro ejemplo de esta drástica situación es el denominado Plan Piloto ${ }^{2}$ impulsado por el Tribunal Superior de Justicia de la Provincia de Córdoba (Argentina), con el auspicio de importantes asociaciones científicas de estudio del derecho penal, en el que se impulsa la realización de juicios abreviados iniciales para obtener condenas inmediatas y así contribuir a generar estadísticas que asombren a "la opinión pública”.

\section{EXCEPCIONES A LOS PLANTEAMIENTOS NEOPUNITIVISTAS EN LA REPÚBLICA ARGENTINA}

A esta altura de las circunstancias, con una sociedad latinoamericana persuadida por un discurso penal inflacionario de sectores políticos conservadores y oportunistas, de que el derecho penal debe estar presente en cada rincón y ámbito de todas las relaciones y conflictos sociales, y además servir de herramienta de control y cambio social en cuanto a la eliminación de los individuos que quebrantan la norma, parece poco probable identificar casos que desafíen la corriente neopunitivista de nuestros días. Sin embargo, a continuación se presentarán dos situaciones muy particulares al respecto en la República Argentina: una reciente e innovadora propuesta legislativa de codificación y una valiente decisión jurisdiccional de un Tribunal Federal.

Volumen 8 ।

EXENCIÓN DE PENAS Y MEDIDAS ALTERNATIVAS A LA PRISIÓN EN EL ANTEPROYECTO DEL NUEVO CÓDIGO PENAL ARGENTINO

2 Acuerdo N. ${ }^{\circ}$ 1010, Serie "A" de fecha 22/6/2010 del Tribunal Superior de Justicia de Córdoba (Argentina).
En febrero de 2014 una comisión integrada por representantes de todo el arco político y además destacados juristas, entre ellos el actual juez de la Corte Suprema de Justicia de la Nación Argentina, Raúl Eugenio Zaffaroni, presentó ante el poder ejecutivo el anteproyecto del nuevo Código Penal argentino ${ }^{3}$, con novedosas propuestas que contradicen la realidad represiva descrita, y con miras a reformar el actual Código que data de 1921 con más de novecientas reformas al compás de una agenda mediática que acabaron por desbaratar totalmente su arquitectura, cuyo punto más alto fue la llamada Reforma Blumberg en 2004, que llegó al extremo de dejar totalmente incierta la cuantía de la pena máxima de privación de libertad con el apoyo de una formidable campaña mediática y la debilidad del Congreso Nacional, lo que no fue resuelto por la Corte Suprema de Justicia de la Nación Argentina, por considerarlo una cuestión de derecho común. En definitiva, ese trabajo es fruto de dos años de debate con aportes de diversos sectores sociales, universidades públicas y privadas, científicos, especialistas, organizaciones no gubernamentales, etc. Se estima que el proyecto tendrá estado parlamentario en el transcurso del presente año, aunque en coincidencia con lo relatado en los apartados precedentes las críticas y discusiones sobre su conveniencia ya comenzaron en los medios de comunicación de una manera jurídicamente torpe, sobre todo hacia sus rasgos garantistas y modernos.

En definitiva, resulta oportuno analizar en el presente artículo dos institutos de la parte general que señalan cuándo el juez deberá o podrá prescindir de la imposición de una pena frente a un hecho típico, y en qué casos se podrá reemplazar una pena de prisión con otras medidas alternativas.

\section{EXENCIÓN Y REDUCCIÓN DE LA PENA}

Así, el artículo 19 dispone:

1. Exención de pena. Insignificancia. No se impondrá pena alguna cuando el daño o el peligro para el bien jurídico fueren insignificantes.

2. Exención de pena y aplicación de la pena por debajo del mínimo. El juez podrá imponer la pena por debajo del mínimo previsto en la escala conminada, o incluso prescindir de ésta, en los siguientes casos:

3 Anteproyecto del nuevo Código Penal de la Nación Argentina formulado por la Comisión para la Elaboración del Proyecto de Ley de Reforma, Actualización e Integración del Código Penal de la Nación (Decreto P.E.N. 678/12). Ver cita n. ${ }^{\circ} 8$. 
a) Pena natural en hechos culposos. En los hechos cometidos por imprudencia o negligencia, cuando las consecuencias hubieren afectado gravemente al autor o partícipe.

b) Pueblos originarios: sanciones. Cuando el agente fuere parte de un pueblo originario, el delito se hubiere cometido entre sus miembros y hubiere sufrido una sanción conforme a sus costumbres. Se atenderá a la magnitud de la sanción sufrida y a la gravedad del hecho.

c) Hechos conforme a la cultura originaria. Cuando la conducta fuere conforme a la respectiva cultura originaria, salvo que se tratare de delitos contra la vida, la integridad física o la integridad y libertad sexual, cuya impunidad importare una grave lesión a la dignidad humana.

3. Aplicación de la pena por debajo del mínimo. El juez podrá determinar la pena por debajo del mínimo previsto en la escala conminada, en los siguientes casos:

a) Menor significación. Cuando el daño o el peligro para el bien jurídico fueren de escasa significación. El juez podrá imponer la pena de multa reparatoria.

b) Pena natural en hechos dolosos. En las circunstancias del apartado a) del inciso $2^{\circ}, y$ tratándose de hechos dolosos, cuando mediare una significativa desproporción entre la lesión sufrida por el agente y la causada por éste al bien jurídico.

c) Penas o lesiones ilícitas infligidas por funcionarios. Cuando el agente hubiere sido objeto de tortura, tormento $\mathrm{o}$ vejaciones por acciones $\mathrm{u}$ omisiones de funcionarios encargados de su detención, cuidado o transporte, o hubiere sufrido un grave daño en su salud por la inseguridad de los lugares de detención o los medios de transporte.

Este artículo clasifica los supuestos en tres incisos que corresponden a tres posibilidades diferentes: el inciso 1 prevé el caso en que el juez debe prescindir de imponer pena; el inciso 2 prevé supuestos en que el juez puede prescindir de pena o bien imponerla por debajo del mínimo, según las características particulares del caso concreto; en el inciso 3, conforme a las mismas pautas concretas, el juez solo puede imponer la pena por debajo del mínimo de la escala legal. Es bueno hacer notar que en la legislación comparada, el Código alemán de 1974, por ejemplo, opta por prescindir, en general, de los mínimos, para dejar mayor amplitud de criterio al juez, y el caso de insignificancia se ha enunciado precisamente en la doctrina de ese origen.

1. Insignificancia. $\mathrm{El}$ único caso en que el juez estaría obligado a prescindir de la pena es el del inciso 1 de este artículo. Se consagra como principio general derivado de la Constitución, por lo que la lesión o el peligro para el bien jurídico es un requisito fundamental para la imposición de una pena. Pero no cualquier lesión o peligro cumplimentan ese requisito en los casos concretos, sino solo los que alcancen un grado de mínima relevancia, porque el poder punitivo del Estado no se habilita para conflictos baladíes ni incluso por razones prácticas la justicia penal puede desperdiciar recursos para atender infracciones que apenas rozan los bienes jurídicos o que, más que lesiones o peligros, implican simples molestias. Muchas de estas conductas insignificantes, pero que son susceptibles de causar algunas molestias, podrían hallar ubicación en un orden sancionatorio de menor gravedad o cuantía que el penal, como puede ser el administrativo o el contravencional.

2. El inciso 2 regula tres supuestos en que el juez, conforme a las características particulares de cada caso en concreto, puede decidir prescindir de pena o bien imponerla por debajo del mínimo de la escala legal. Queda implícito que también puede no hacerlo cuando considere que el caso no encuadra en los supuestos mencionados.

A. Pena natural en hechos culposos. Hay dos principios que están comprometidos en los llamados casos de pena natural. Son el de humanidad y el de proporcionalidad, aun sin entrar en la compleja cuestión de la utilidad de la pena. Por lo general, se trata de casos drásticos, en los que el agente ha sufrido consecuencias sumamente dolorosas. El texto proyectado dice "cuando las consecuencias hubieren afectado gravemente al autor o partícipe", con lo que se entiende que la afectación puede ser tanto física como moral, es decir que no se limita a los casos en que este haya sufrido un daño en su cuerpo o en su salud, sino también cuando le hubiese ocasionado una pérdida que lo afecte emocionalmente, como pueden ser lesiones o muerte a sus allegados o ruina patrimonial.

B. Pueblos originarios: sanciones. En nuestro país viven pueblos originarios, cuya cultura se ha desconocido con demasiada frecuencia, pese a que en muchos casos disponen y practican formas de solución de conflictos entre sus miembros que, en sus comunidades, resultan más eficaces que el ejercicio del poder punitivo practicado sobre la mayoría de la población. Cuando se produce un conflicto entre personas que pertenecen a las culturas originarias, es inevitable que la comunidad ponga en funcionamiento sus procesos de solución, por lo general de carácter reparador, que en su grado máximo importan la expulsión de la comunidad, sanción de máxima gravedad, pues para el partícipe de la cultura implica una pérdida de identidad. En caso de conflicto entre miembros de la 
comunidad originaria, imponer la pena prevista en el Código Penal desconociendo esta circunstancia importa admitir, en el plano material, una doble punición (la originaria y la estatal).

C. Hechos conforme a la cultura originaria. E1 tercer supuesto contemplado por este inciso difiere del anterior, pues prevé los casos en que la conducta realizada se halle en conformidad con las costumbres emanadas de la cultura originaria. En síntesis, se cuestiona hasta qué punto puede exigírsele a una persona que comparte una cultura que incorpore los valores de otra sin caer en una reiteración de imposiciones colonialistas que serían inadmisibles.

3. El inciso 3 de este artículo se ocupa de los casos en que solo se faculta al juez a imponer una pena por debajo del mínimo legal, sin habilitarlo a prescindir de pena.

A. Menor significación. La lesión o el peligro para el bien jurídico es un continuo que va desde lo insignificante hasta la máxima gravedad. Si por bien jurídico entendemos aproximadamente una relación de utilización o empleo para la existencia de los habitantes, esta relación se puede molestar, perturbar, dificultar, impedir temporalmente, obstaculizar permanentemente o hacer imposible su restablecimiento, o bien generar iguales peligros sin concretarlos. Todo dependerá del bien jurídico de que se trate y de la modalidad de cada caso. Para eso es menester que el juez disponga de la posibilidad de adecuar la pena a la medida de la lesión o del peligro en cada caso, donde la realidad ofrece todos los matices e intensidades de afectación, que van desde la insignificancia, en que se le manda que no imponga pena, hasta todos los grados en que media significación lesiva o riesgosa.

B. Pena natural en hechos dolosos. Las mismas razones que hemos mencionado en los delitos culposos operan en los dolosos. La mayor gravedad del delito doloso obedece a que, por lo general, una conducta planificada para obtener el resultado siempre es más riesgosa que una conducta negligente, lo que aconseja una mayor prudencia en la facultad otorgada por el juez.

C. Penas o lesiones ilicitas infligidas por funcionarios. Este párrafo abarca una hipótesis no muy desarrollada por la doctrina proveniente de países centrales, pero que se presenta con desgraciada frecuencia en el medio latinoamericano, donde el ejercicio del poder punitivo se desborda y los propios agentes del Estado, por acción o por omisión, dolosa o culposamente, dan lugar a lesiones o infligen dolor ilícitamente a las personas imputadas o condenadas por delitos. Es sabido que muchas veces se constatan estos hechos con peritaciones médico-forenses, pero no se descubre a los autores, en general encubiertos por los propios agentes estatales. Para evitar este absurdo, se propone facultar al juez a una prudente disminución de la pena. Esta disminución asume el carácter de una compensación de la pena legal en el momento de imponerla, restándole la pena ilegal realmente sufrida.

\section{PENAS ALTERNATIVAS A LA PRISIÓN}

Por su parte el artículo 22 prescribe:

$$
\begin{aligned}
& \text { En los casos y condiciones previstas en este } \\
& \text { Código, la pena de prisión podrá sustituirse } \\
& \text { por las siguientes: } \\
& \text { a) Detención domiciliaria. } \\
& \text { b) Detención de fin de semana. } \\
& \text { c) Obligación de residencia. } \\
& \text { d) Prohibición de residencia y tránsito. } \\
& \text { e) Prestación de trabajos a la comunidad. } \\
& \text { f) Cumplimiento de las instrucciones } \\
& \text { g) Mudiciales. }
\end{aligned}
$$

La innovación más importante del presente anteproyecto es la supresión de la genérica libertad condicional. Esta institución, que delimita una forma de ejecución de la pena de prisión cuando el individuo condenado ha cumplido los dos tercios del tiempo de su condena y ha observado positivamente los reglamentos carcelarios, pasaría a ser reemplazada por un abanico de penas alternativas que suplirían las meras condiciones del artículo 13 vigente. En primer lugar, debe tenerse en cuenta que la ejecución de las penas alternativas requiere un cuerpo de personal especializado dedicado a su ejecución, que es sustancialmente diferente del encargado de la ejecución de la pena de prisión. Si bien esto implica un costo presupuestario, no debe perderse de vista que, en definitiva, representa un considerable ahorro, pues el crecimiento permanente del número de presos, además de acarrear violaciones a derechos humanos, importa un alto costo, dado que la pena más cara para el Estado es la de prisión.

Su aplicación efectiva importa un cierto grado de cambio en la cultura jurídico-penal, habituada hasta el presente a imposición de penas en forma lineal de tiempo y con muy poca atención a las particularidades del conflicto concreto y de las personas involucradas.

Ningún país del mundo prescinde de la prisión en los casos graves; tampoco se abusa de ella en infracciones de menor cuantía, aunque no falten casos de alarmante abuso de la prisión y de absurda y peligrosa sobredimensión del aparato carcelario, situación que se ha agravado en las últimas tres décadas. Pero lo cierto es que, fuera de cualquier extremo represivo o libertario, existe una importante franja de delitos de gravedad media o 
menor en que el uso de la prisión es discrecional para el legislador, o sea que depende de una decisión política, sin que se pueda afirmar la existencia de reglas de política criminal universalmente aceptadas.

\section{DECLARACIÓN DE INCONSTITUCIONALIDAD DE LA PENA MÍNIMA EN EL DELITO DE COMERCIALIZACIÓN DE ESTUPEFACIENTES}

En primer término, resulta menester señalar que el actual y vigente Código Penal argentino adopta una clasificación de penas según su divisibilidad de la siguiente manera: indivisibles, con una única sanción que no permite al juez margen alguno de tasación (como puede ocurrir con la pena de prisión perpetua para los casos de homicidios agravados), y divisibles "que permiten al juez seleccionar la que considera adecuada entre distintas magnitudes, observando los máximos y los mínimos fijados por la ley" (Creus, 1994, p.38). Así, encontramos en la Ley 23.737 de Tenencia y Tráfico de Estupefacientes $^{4}$ que el artículo 5 , inciso c) prevé que

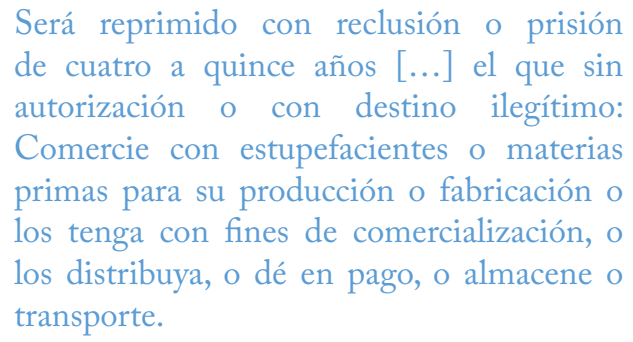

Además, se adopta un sistema difuso de control de constitucionalidad, por lo que cualquier juez del territorio argentino puede declarar en una causa en la que se encuentre avocado como juzgador la inconstitucionalidad de una norma.

El Tribunal Oral en lo Criminal Federal N. 2 de Córdoba, con fecha 16 de agosto de 2013, al entender en un juicio por el delito de infracción a la Ley 23.737, resolvió declarar inconstitucional el mínimo legal de la pena prevista por el legislador, para aplicar al caso concreto una pena inferior a la escala legal ${ }^{5}$. Fundamentó su decisión, teniendo en cuenta la situación de vulnerabilidad de la imputada traída a proceso y la escasa afectación al bien jurídico tutelado por la norma que se le reprochaba; por lo que el tope mínimo indicado en la escala penal prevista por el artículo 5, inciso c) de la Ley 23.737 excedía la medida de culpabilidad, en

4 Ley promulgada el 10/10/89 y publicada en el B. O. el 11/10/89. franca violación a los principios de proporcionalidad y de humanidad que proscriben la imposición de penas inhumanas, crueles e infamantes.

El Tribunal de juicio entendió que en el caso planteado se verificaban circunstancias excepcionales por las cuales aplicar una pena de cuatro años de prisión a la acusada, tal cual lo solicitara el señor fiscal, vulneraría el principio de culpabilidad. Ello en atención a que la imputada no pertenecía a una organización dedicada al tráfico de narcóticos con amplia capacidad operativa, técnica o económica. Por el contrario, se trataba de una mujer que ejercía la prostitución, y vendió droga en una sola oportunidad en el domicilio que habitaba y en pequeña cantidad; además ese estupefaciente era cocaína, sustancia a la que confesó su adicción, pues le traía alivio a las fuertes cefaleas que sufría por su operación en la cabeza cuando era niña. En este orden, la Corte Suprema de Justicia sostuvo que, en el momento de individualizar la pena aplicable, el principio de culpabilidad impone que la sanción sea proporcionada al hecho cometido y que aquel principio impide que se aplique una pena mayor a la culpabilidad del imputado (fallos: 314:441, 318:207 y 329:3680); en consonancia con lo manifestado por la Corte Interamericana de Derechos Humanos en el Caso Herrera Ulloa contra Costa Rica rta. 2/7/2004, donde específicamente sostuvo que la punición debe ser racional, ajustada a la jerarquía de los bienes tutelados, a la lesión que se les causa o al peligro en el que se les coloca y a la culpabilidad del agente. En definitiva, imponerle la pena de cuatro años de prisión, por más que fuera el mínimo legal posible, constituiría para aquella una sanción evidentemente desproporcionada, contraproducente e innecesaria desde el punto de vista del fin de prevención especial que se asigna a la ejecución de la pena privativa de libertad, o sea, la resocialización (art. 10, ap. 3 del Pacto Internacional de Derechos Civiles y Políticos; art. 5, ap. 6 de la Convención Americana sobre Derechos Humanos; art. 1, Ley 24.660). Además, en este caso concreto, una pena de tal magnitud (cuatro años de prisión) implicaría una clara vulneración del principio de mínima suficiencia, que limita la aplicación del derecho penal a lo estrictamente necesario y halla su razón en los principios de lesividad y proporcionalidad, los cuales tienen fundamento en el artículo 19, primer párrafo, de la Constitución Nacional. En consecuencia, se declaró autora penalmente responsable a la acusada del delito de comercialización de estupefacientes, pero se le impuso la pena de dos años de prisión para su tratamiento penitenciario.

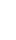


En consecuencia, se observa que la magnitud del ilícito no afectó de manera considerable el bien jurídico tutelado que, vale recordar, es la salud pública en general (delitos de peligro) y no la integridad corporal individual. En estos términos, los jueces señalaron que los mínimos de las escalas penales conminadas en abstracto no solo pueden resultar problemáticos por razones estrictas de la categoría culpabilidad, sino que también pueden ser excesivos en atención a lo que constituye el soporte de la culpabilidad, es decir, al injusto mismo "se trata de supuestos en los que la lesión al bien jurídico no es insignificante, pero de cualquier modo es inferior a la entidad que demanda una pena conforme al mínimo de la escala" (Zaffaroni, Alagia y Slokar, 2002, p. 955).

\section{DISCUSIÓN}

Parece ser que el derecho penal seguirá marginando duramente a los ya marginados; es un sistema lamentable, en el cual el estado de excepción y la emergencia constitucional han devenido regla, y los dispositivos temporarios de crisis se han transformado en instituciones durables y permanentes (Agamben, 2005).

¿El derecho penal puede y debe ser utilizado como una herramienta de control social en todos los conflictos humanos? Definitivamente, no. Resulta menester defender la tesis de un derecho penal liberal ilustrado, coherente con un Estado de derecho constitucional, que tipifique la menor cantidad posible de conductas exteriorizadas individuales y hacer caso omiso a las pretensiones punitivas de una sociedad sobreinfluenciada por los medios de comunicación; por lo que la ciencia jurídica penal debe desempeñar un papel protagonista en la discusión y comunicación, y llevar un manto de racionalidad y mesura. Así, se concluye que el derecho penal debe mantenerse inmutable en tiempos sociales convulsionados que demanden su intervención omnipresente para modificar aspectos conflictivos de la sociedad, y de ningún modo justificar la flexibilización de garantías fundamentales en pos de una falaz eficiencia de seguridad ciudadana. Además, se deben rechazar los postulados que abandonen la teoría del bien jurídico tutelado y dejar de considerar la pena privativa de la libertad como la única y más eficiente forma de reinsertar socialmente a los delincuentes. En este sentido, propuestas alternativas a la prisión deben ser puestas en funcionamiento para delitos de menor cuantía. El problema, amén de la expansión del derecho penal en general, es también específicamente la expansión del derecho penal de la pena privativa de libertad. Esta última es la que debe realmente ser contenida. Por otro lado, los mecanismos de democracia semidirecta, como iniciativas populares de ley, deben ser inadmisibles en materia penal, así como también las propuestas legislativas inflacionarias en periodos electivos no deberían formar parte de las plataformas electorales.

Por último, sin llegar a proponer una radical reducción del derecho penal a la protección de la vida, la salud, la libertad y el patrimonio, sí parece conveniente sugerir que la mayor parte del fenómeno expansivo del derecho penal habría de ser, sin más, reconducido al derecho administrativo sancionador. Aunque se debe tener en cuenta la constatación de una realidad respecto de la cual se estima poco probable la vuelta atrás. Por ello, a partir de lo dicho, se postula una opción matizada.

Estimando improbable (quizá imposible) un movimiento de despenalización, sí se propone que las sanciones penales que se impongan allí donde se han flexibilizado las garantías no sean penas de prisión. Ello tiene dos consecuencias. Por un lado, ciertamente, admitir las penas no privativas de libertad como mal menor dadas las circunstancias respecto de infracciones en las que se han flexibilizado los presupuestos de atribución de responsabilidad. Pero sobre todo, exigir que allí donde se imponen penas de prisión, y especialmente penas de prisión de larga duración, se mantenga todo el rigor de los presupuestos clásicos de imputación de responsabilidad (Silva, 2003, p.).

\section{REFERENCIAS BIBLIOGRÁFICAS}

1. Agamben, G. (2005). Estado de excepción. Buenos Aires: Adriana Hidalgo.

2. Albrecht, P. (2000). El derecho penal en la intervención de la politica populista. Granada: Comares.

3. Arroyo, L., Neumann, U. y Nieto, A. (2003). Crítica y justificación del derecho penal en el cambio de siglo. Cuenca: Universidad de Castilla-La Mancha.

4. Bar, C. L. von (1992). Geschichte des deutschen Strafrechts und der Strafrechtsheorien. Ámsterdam: Scientia Verlag. 
5. Binding, K. (1902). Lebbuch des Gemeinen Deutchen Strafrechts. Berlín: Engelmann.

6. Burchard, C. (2012). El principio de proporcionalidad en el derecho penal constitucional, o el fin de la teoría del bien jurídico tutelado en criminales en Alemania. Bogotá: Temis.

7. Creus, C. (1994). Derecho penal. Parte general. Buenos Aires: Astrea.

8. Ferrajoli, L. (2001). Derecho y razón (trad.P. A. Ibáñez). Madrid.

9. Hillenkamp, T. (1981). Vorsatztat und Opferverbalten. Gotinga: Schwartz.

10. Jakobs, G. (1997). Derecho penal. Parte general. Fundamentos y teoría de la imputación. Madrid: Marcial Pons.

11. Pastor, D. (2005). La deriva neopunitivista de organismos y activistas como causa del desprestigio actual de los derechos humanos. Nueva Doctrina Penal, 1,73-114.

12. Prittwitz, C. (2000). El derecho penal alemán: ¿fragmentario?, ¿subsidiario?, ¿ultima ratio? En C. M. R. Casabona, La insostenible situación del derecho penal. Fráncfort: Editorial Comares.

13. Maier, J. (2006). La esquizofrenia del derecho penal. En I. Rivera Beiras, Contornos y pliegues del derecho: homenaje a Roberto Bergalli. Madrid: Anthropos.

14. Silva, J. (2003). Retos cientificos y retos politicos de la ciencia del derecho penal. Madrid: Universidad de Castilla-La Mancha.

15. Von Liszt, F. (1999). Tratado de derecho penal. Valletta Ediciones SRL.

16. Zaffaroni, R. (2010). Fundamentación al anteproyecto del Código Penal Argentino. Recuperado de http://www.pensamientopenal. com.ar/buscar?search_api_views_fulltext $=$ anteproyecto $\% 20$ codigo $\% 20$ penal $\% 20$ comision $\% 20$ zaffaroni

17. Zaffaroni, E. R., Alagia, A. y Slokar, A. (2002). Manual de derecho penal. Parte general. Buenos Aires: Editorial Ediar. 